\title{
SOCIOECONOMIC AND ORGANIZATIONAL CONTEXT OF MANAGEMENT
}

\author{
Tatiana Shterma \\ Private Higher Educational Institutions "Bukovina University", Chernivtsi, Ukraine
}

\section{(C) MESTE NGO}

JEL category: D2, D23, Z1

\begin{abstract}
This paper deals with the development of management that takes place in many areas and covers a wide range of activities, aiming at improving communicational and representational skills. It also includes the development of specific skills such as management of information in the office, assessment of performance, financial management, governance in different cultures and alignment capabilities (training) management in accordance with changes in strategies and organizational structure. The management is characterized by a variety of approaches, methods, interpretations and ideas related to human and organizational development.
\end{abstract}

Contemporary management is in a stage of transition specialists to control the deformation between the managerial hierarchies, and also the trust that is necessary if people need to take initiative. During this transition, manager's development is faced to many dilemmas and severity of consequences. Managers may fear that their specialization might be followed by retrenchment of working positions. This development of their knowledge and skills will help them improve themselves and prepare them for a career change.

The most powerful sources for management development are the global technology and personal knowledge and skills development.

Keywords: management, management development, manager, organization of work, creativity

\section{INTRODUCTION}

The development of management in many areas is a wide range of activities: from self-development to communication and representation skills. It also includes the development of specific skills such as managing information in the office, performance evaluation, financial management, managing in different cultures and alignment capabilities (training) management in accordance with the

Address of the corresponding author:

Tatiana Shterma

麦=" sht.tatjana@gmail.com changes in strategy and structure. This area is characterized by a variety of approaches, methods, interpretations and ideas related to human and organizational development. However, "a large variety has its drawback. Many of us fall into a behavior like a bee that gathers honey from each droplet on flower ... balance must be found between the need to investigate ... and the need to work carefully while on a well thought out position" (Weissman, 1992). 
Global flows of money and information have a direct impact on the development of management, which was originally formed during periods of relative stability, when it was likely to ignore volatility. Management is in transition from a command and control structures, the corresponding relationship stability, distributed decision-making structures needed in the rapidly changing conditions. From managers are now required new approaches to decision making under uncertainty, and they also have to put much more effort to create an atmosphere where people can cope with the instability not only in decision making but also in the course of their employment. The best method of organizing work in Management Development - a project of the individuals included in the project boundary of the organization.

As it is known, the word "management" is used in three ways:

- Management science,

- Process management, leadership

- Category of people who are managing (managers).

We consider the problem of management as vocational qualification group managers, executives.

1990s - Important time trials for both managers and for management development. Global flows of capital and information affecting any organization, regardless of its scale or location. Managed or planned, the economic system is collapsing worldwide growth and relative stability is no longer considered as large organizations can no longer control the economic development. Instead, these organizations are now "more modest perception of their authority," and they "share a common destiny" in the face of dynamic complexity that characterizes the global environment (Pareto, 1906). The impact of this complexity on the structure of organizations on what is expected of people who work in them, and understanding the power and authority clearly focused on specific managers who sit at my desk, thinking about how to set priorities. In this situation, managers and those responsible for supporting their development, on one hand, experience confusion, on the other hand, are faced with new opportunities.
Confusion easily happens when managers feel that they are called up to act one way, and then they are treated differently. Although theorists have noted "the rapid change in the development of management style - go from style - based control and aggression ... to a style based on mean and friendly relations", there is evidence that some companies still have a long way: CFO of a large organization for the production of media assets so has recommended his own company: "This company depends on the creativity of the people who make program, and it treats them both phony!" (Shein, 1985)

\section{WHERE DOES THE DEVELOPMENT OF MANAGEMENT COME FROM?}

In the past, development management provided systematic training based on a detailed job description conducted in accordance with the standard schedule and was learning new skills and abilities. A manager had to answer to every problem and be sent on courses. This approach is faced with a "transfer learning problems in practice" and the focus is shifted to individual learning and the process of learning.

However, socio-economic and institutional context within which management evolved remained relatively unchanged. Providing income to shareholders remains the primary goal of most companies, dominated by commanding and controlling hierarchy, jobs are very specialized, planning is separated from its actual implementation and management reserved set of methods, with which you can perform a certain task. A management task was to make a rational choice from a set of options and then develop a new logical explanation for the behavior, based on the analysis of control problems faced currently. The approach, known as Taylorism watched "initiative and incentive" as a barrier to the effective mass production and defended the "substitute science for the individual judgment of the employee" (Skone, 1995). Most decisions are taken in situations where you can learn all the facts, allowing managers to analyze, predict and use their knowledge and experience to guide data collection, findings, and control deviations from the steady flow of events. In this environment, people have been properly instructed and 
supervised, and prevented them communicate with each other.

The economic system that came into the arena later, faced with the need to be determined before the competition and rapidly accumulate most of the capital. This need gave birth to a motley collection of specimens' relationships with financial institutions, customers and employees. Entering the market at a time when technology was already quite complex, companies are faced with higher capital (fixed capital costs per employee). Many, therefore, chose broad skills rather than narrowly focused to encourage people to express their views in the light of the economic usefulness of exchanging information directly into the workplace and change the specialized production time for the length of time during which you can share information.

Management, especially in mature economies is under control of professionals that come between the government hierarchies, the trust that is necessary if people need to show the initiative. During this transition management development is faced with the same dilemmas and severity of consequences and specific managers. Managers may well fear that after their development followed by retrenchment, and this development will help to improve themselves and prepare for a career change.

In a controlled economy, government is the primary mechanism for control within the organization. But in order to remain viable in the turbulent surrounding atmosphere, where no group controls the fate of the business as a whole, the organization should be much more responsive to price and thus to cost. To remain viable in the global economy, where the emphasis is on information management instability, innovation and teamwork, organizations need to better know their human assets and mechanisms for trust management including them in the process. However, the mechanism of power embodied in the command and control hierarchy is very strong, and market considerations should dictate strict financial control, significant downsizing is often the consequence.

Management development in the mid-1990s. Located at the stage of transition from command and control and to save money and culture. But while the command and control style does not conflict with each other and can generate in terms of stability in the workforce loyalty and a sense of security and reliability, reduce costs and complicated culture fit together. This conflict can have a major impact on the management and development.

Companies have great expectations from their managers. According to the opinion of one of the managing directors, the manager must be impresario, "can engender enthusiasm and focus in one direction desire of many individuals with different talents. He listens, he creates a vision and structure, and he is inspiring. "According to another director, a manager should be a sculptor, "forming a manager who can make good decisions, and not to be smoothly polished piece of yesterday" (Martin \& Midgley, 1996). Other ideas about the role of manager: manager must "leave everything and do not rush the progress of events" or be the conductor of an orchestra, a gardener, a guide, a volunteer instructor or advisor. According to J. Pariha, "the role of management is to create an atmosphere within the organization, the culture and the context in which corporate enrichment and personal achievements undertaken in conjunction with each other and are in resonance with the progressive development of the creative process and integrated global community" (Meskon, 1992).

Since managers are expected to be effective manage profitable divisions, skillfully control costs to compete with other departments, subjected to inspection and audit themselves, and be rewarded accordingly for performing certain work - all at the same time.

Most of the structures and systems of support market mechanisms by government command and control hierarchy, and it's a powerful combination. At the same time, awareness of the presence of people in the innovative capacity needed to implement market opportunities and use their judgment in dealing with uncertainty and perceptions of trust as a "grease" social tie outside the role of content manager. He gets under their means much attention that the current management development given culture, people, communication, interpersonal skills and team building skills. But nevertheless the structures are managed on the basis of power, despite the smaller number of hierarchical levels and growing 
economic role and power of global networks and alliances. The contradictions inherent to these expectations on the role of manager - it is one and the same time be authoritarian and egalitarian both - lead to significant problems. They are briefly summarized by T. Peters: "Approximately $97 \%$ of your people - creative, strong, loyal, caring and generous, with the exception of eight hours, when they will do for you. We need to ask yourself a serious question: what kind of a bottomless abyss as managers we created that selected these talents and turned them into disabled people?" (Morhunov, 2001)

An effective manager's job includes training that gives the ability to deal with complexity, diversity and uncertainty. Success depends on trust: trust managers to their own inner resources and intuition and take responsibility for creating a climate in which their subordinates can do the same. "For over thirty years the world of management, whose main task was to create a business treats intuition as a dirty word ... but now that companies are looking for the ways to create big business and go after more than a decade of excessive rationality and disaster strategic planning, intuition returns to us. The problem lies in how to combine it with the need for accurate and deep understanding of markets, technologies, strategic and competitive behavior, which managers need in times of global competition, complexity, instability and rapid change" (Mylner, 2006). When details of the actual situation recognizable, more likely in a stable economic and market conditions, managers can use their knowledge and experience in order to analyze the situation and make the right decisions. However, as an important part of the work associated with uncertainty, managers are forced to go beyond making a decision based on full information. Management problem goes beyond logic, managers must rely on their judgments and choices, and now for this choice, not the information should be responsible (Burng\& Stalker, 1961).

As a result, the new value, insight, intuition and implicit knowledge are increasingly becoming common decision-making by people due to the interaction between what is clearly written and the fact that defies precise formulation and the process of thinking that led to the decisions may not always be clearly stated. This can lead to problems for those managers who have been trained and competent analysis of rationalism, monitoring and controlling those who work for them, so they do the same as they are. Managers are faced on one side with the new requirement to use intuition, on the other - a concern that important decisions - their own as well as their managers and subordinates - based on something elusive and "unscientific". Intuition, which leads to a highly valued opinions voiced, but it also depends on the elusive and very delicate balance between what and how people feel that they can understand and do, and those difficult tasks they face. Managers are overly occupied, or insufficiently immersed in their work, are much more likely not to trust their instincts: they probably will feel that their support is fragile and unreliable as a basis against destruction, as they concern increases, competence, in accordance with decreases.

Program for Management Development in the South African company Anglo American Corporation has been specially designed to minimize excessive stress and unreasonable doubt. The program includes the development of service centers that use a procedure known as "Evaluation of career path" to assess the current capacity of individuals to make decisions in the face of insurmountable uncertainty. Evaluation provides the basis for development for individual programs that coordinate with increasing responsibilities superstitious growth of this ability in the future. One of the primary goals of this program is to determine the ability of managers of Negro origin and providing them with appropriate opportunities to move forward. Until recently, managers of Negro origin were virtually in no demand, and the purpose of this program was to ensure that in the future they would not be either too overwhelmed or insufficiently used. To achieve this, it was necessary to use a procedure that is quite free from the influence of cultural warnings. It is because this balance is so fragile, it requires from people to use their intuition which means asking more than they can and are willing to give. Physical conditions may be important, but cultural aspects - how created expectations evaluated learning what behavior is encouraged or discouraged - are probably the most important.

In command and control hierarchy responsible managers are simply controlled. In the transition 
to new models of management of waiting as support strict financial control, which can make them feel absolutely ruthless and create a climate in which those who work for them, "educate", "encourage" and "cared for".

In terms of climate in which managers are expected to use their judgment to trust intuition and encourage others to do the same, the development of management should include concepts such as learning how to learn, to be able to listen, to be part of a team, to influence others, communicate and understand the presence of the individual's ability to grow. As managers perform new and broader challenges of development should occur at a pace that is not too pushed, does not lead to anxiety and loss of confidence. Otherwise, the effect will be negative.

As a good practice, these concepts are woven not only with the overall development of the organization as it also modifies itself to meet the challenges of their environment, but also with an understanding of why these changes in culture and behavior are necessary. When these relationships are clear, difficult relationship between tight financial controls, job cuts and concern for people can be understood better. Need of creative people who will act on its own initiative, serving customers or creating products, because the survival of the organization depends on its ability to be flexible and adaptive in a highly competitive environment, and the behavior of individuals is a source of flexibility. Organizations need people who will work together as a team, so that the efficiency in the rapidly changing environment depends more on people than on their accumulated money, information and insight. In command and control hierarchy where considerable force is position, not all information is available, and that value that it might have lost. If there is a constant high level of human capital, represented in the person of each employee, organizations need to maximize the use of their investment.

The era of lifetime employment is over and not guaranteed next working heavy burden on managers, causing concern and their fate and the fate of those who work for them. It was assumed that there was a return to the relationship "master - servant" during early industrialization, when workers have minimal rights. For many workers this is true. In the countries where the creation of conditions of well-being are considered to be too expensive for the government and organizations, entrepreneurs can make contracts so that they do not have to contribute to the national security. Particularly women and young people can be hired on a part time basis and without any rights. In the states that are fighting for the creation of the economy may be varying degrees of legal protection against such tyranny, by establishing employment conditions for recognition of trade unions.

Management in terms of abundance of different types of contracts - a new experience for managers and that what they need for their development. There are technical and legal problems that they need to deal with, and there are expectations that the relationship represented in the contract, will cost in accordance with the "culture of caring and respect for mutual interests " (Anon, 1988). This kind of expectation can be a real moral dilemma that managers face with. They are encouraged to treat people not as a production unit, but as individuals with strong potential. There is a lot of talk on "management paradox" paradox that encourages managers to plan the culture of education and encouragement in a situation where, at any time a dismissal can occur. Managers need help to understand the nature of contracts as from a technical and cultural point of view. There is also a need to ensure transparency in areas of the organization.

To develop self-knowledge, best practice has to be offered. That means using a variety of psychological tools to help people reflect on themselves and on how they perceive others. These tools may include Type Indicator MyersBriggs people (Myers Briggs Type Indicator), 16factor personality questionnaire R. Cattell (16 PF Personality Factor), personality assessments, critical thinking tests and communication of equal position and the subordinates. For evaluation of individuals these instruments without feedback may not be the best method, but there are organizations that do not distinguish between assessment and development.

Successful practice places the development of management in the business, facilitates strategic development and definition of long-term direction. The survey of CEOs worldwide in 1990 showed 
their priorities in the development of management: strategic competence (mentioned $71 \%$ of all respondents), adaptability to new situations $(67 \%)$, sensitivity to cultural differences $(60 \%)$, and ability to work in international teams (58\%), relationship skills (40\%), and a high level of focus on the problem (19\%) (Granstrand, 2000) (Hinterhuber, 1991) (Congress, 1995).

Widely used approach "to base - competence" combines the development of management and organizational development, combining a thorough analysis of the role of a full assessment of the competence of the individual. As with psychological tools, this approach can enhance the individual self, it becomes increasingly important to the extent that people in and out of the various organizations in different periods of their working lives and which also may constantly seek a balance between work and other aspects of their lives.

One company president described the role of experience in the decision as follows: "Good decisions depend on the expertise and experience depends on bad decisions" (Koch, 1998) (Koch, 1999). What matters is not what people have done or what they have been working in a certain area, but what they have gained experience. Understanding how the interaction between knowledge, experience and solutions change in the transition from stability to turbulence may convince managers that they have the knowledge, experience and decision in a stable environment. In case they do not know something, it is only because of the lack of education, experience or consideration: "Although knowledge - one of the essential instruments of labor, it is - not the work ... the mere knowledge does not bring you to the end ... The work problems you encounter cannot be completely correct answer. You should use the knowledge and solutions in combination" (Mylner, 2006). Considering knowledge as a tool, people are exempt from guilt because they do not know something and it helps them not only to the current uncertainty, but that uncertainty is increasing in many situations where decisions need to be taken.

Knowledge is no longer a static model, we transfer from one situation to another, but a way to adapt and re- coordinate the familiar model of vision, discussion and action in new situations. In a labor environment's ability to monitor the state of affairs in the world, create both implicitly and explicitly formulated knowledge and bind them together in a "spiral process" provides a crucial corporate advantage. Again, this means a significant change in knowledge, experience and solutions in understanding their role managers' habituation to the use and control of the use of existing knowledge, which was typical for the command and control management hierarchy and stable conditions. Not only do they have to come to terms with the fact that previously acquired knowledge and skills, sometimes for many years, evening or distance learning may not be adequate for long, but must also create a climate to share information and generate new knowledge. A compromise must be reached through awareness, and this, in turn, requires a full understanding of the problems. Best practice of management is to support managers in decision-making, helping them to better understand the working of their own intuition. Understanding context, managers will be able to not only bring costs in line with the culture, but also combine them in ways that make sense for their own sake, for the people who work for them and for the company that employs them. Managers too often left without this contextual understanding, while all of them are still waiting, they are part of "an organization that learns". "XXI Century Company shall promote and educate a way to improve and implement innovations. This idea is radical. It means that learning is a central tenet of the organization. It replaces control as fundamental labor management problems" (Poole \&Uornera, 2002). "The success of the market increasingly depends on learning, yet most people do not know how to learn". The best practice in management development - focus on the learner and the learning process - frees people from the idea that exactly what they are studying is the most important, and if something is not "properly investigated" they tolerate failure. The question of culture arises in the atmosphere in which people are encouraged to "respect their mistakes" and do not hide the fact that they went forth, so that learning could take place. Command and control hierarchy encourages concealment of errors, "shifting the responsibility to others" and move away from responsibility. The transition to a culture of respect mistakes can be made only by force of example, the culture of avoidance of responsibility too deeply ingrained to change under the influence of only words. Managers may 
try to create a learning environment, but if they recall their errors affecting the payment of their results, the protection of their own position becomes paramount. (Vyssema, 2000).

There is yet another point in connection with which managers; especially middle managers may be torn between persuasion and reality. All organizations are now more outward, observing signals or signs in the environment that could be indicative of new opportunities or threats. Information required from any possible source, but the command and control unit, within which are taken into account only knowledge which are at the heart of government, and only the center has the ability to transform information into knowledge hinders mid-level managers and prolongs reply actions. However, middle managers, who are expected to control costs and provide cultural changes, have a great opportunity to do something, and another, benefiting the company, generating information collected based on the experiences of people on the periphery of organizations working directly with customers or at work. These managers know that they could be a powerful driver of change, they are in key positions to combine strategic micro data (without context, that is, without regard to the organization), practical micro data (contextual), which can serve as a starting point for action to be made of both upper and lower levels. Management development can support mid-level managers in these positions, if reinforce understanding of the commercial value of the information obtained at the periphery, the ability to communicate this information to the superior management skills and encouragement of employees to their people that they shared information and jointly discuss new ways to perform tasks and practical improvements.

Two groups of words are often found in articles on the development of management. The first group concerns the state of tension, vigilance and includes the words "listen", "watch" and "caution", reflecting the need for understanding all the nuances that are rich in features but controversial surrounding environment. For example, "understanding" - the first word of the name of the program "AVIRA» (understanding, vision, imagination, responsibility, and action), adopted in France for senior executives. Program «AVIRA», derived from the study of the needs of senior managers in large international corporations in Europe, USA and Asia Pacific, focuses on the relationship between the manager, the organization and the environment. It focused attention on the environment, i.e., customers, competitors, partners, suppliers and coproduction, is transformed into the greatest value if it becomes the responsibility of each and every person who knows his or her intuition to be received with respect. Managers at all levels can make sure that this is the case, but to do that you need a significant change in perceptions of what is important only that the knowledge possessed by the central government organizations (Keynes, 2002).

The need for organizations to become flexible, adaptive and curb information may best be met by integrating human development and design organizations so that the relationship between these two areas of development was agreed in every point. They can be connected by means of correlation of complexity of the work to be done, with the ability of the individual to cope with this complexity.

If problems are similar to all managers, their performance can vary greatly depending on the level of responsibility of the manager. Therefore, the practice of management is the accurate adjustment of program development needs of persons of a certain level of responsibility and training of people to move from one level to the next. An example is the work of the Centre for Management British Gas in 1980 and 1990. When the company British Gas was privatized in 1986, the board of directors concluded that their core business will flourish at the beginning of the next century, after examining alternatives, they settled on a strategy international expansion in the gas and oil sector. In the early 1980 's. Center management British Gas has developed a program of middle management focused on scenario thinking, applied to organizational change and helping managers to see which skills they would need in the coming years (Mylner, 2006).

The second series of programs called program business problems has been designed for superior managers. It is also used scenario approach to management development, training actions and teamwork. These programs have 
become an important developmental experience that has become a counterweight to the strong functional organizational system that was privatization. At the end of 1980s,program experience for middle management, business applications and problems appeared understanding of different cultures have been used in the development of strategic management development programs to improve understanding of the strategic direction of business development senior managers from Canada, America, Africa, Russia, Germany and the UK. All these programs have been developed on the basis of development control, formed during the last thirty years at Brunel University in the UK (Mylner, 2006). British Gas Management Centre has used this structure, when the focus was developments in Eastern Europe and the Centre for three weeks to exercise hospitality to three senior executives from the Russian company "Gazprom". During the discussion it became clear that the head of the company "Gazprom" often works in remote areas where their primary objective is to create a city in which employees can live even before they start to get out of the ground gas or transport it. This means that managers are responsible not only for the management of the organization, but also for farms, schools and hospitals. In many cases, they are among the most important people in the structure of local government. The system of governance facilitated understanding the complexity of this role and, consequently, the required contribution management.

These visits led, in turn, to contact with the Leningrad Institute of Management (LIMA) and SDA Bocconi School of Management in Milan, as well as proposals from Lima joint program directors for British Gas and leadership potential "Gazprom". Two courses were held in St. Petersburg. The first two weeks of each course were provided with Lima, who gave a basic understanding of Western management and economy, while the third week combined program was implemented with the directors of all the business units of British Gas. The starting point for the development of the program was taken over development system managers. This clarification has made it possible to adjust the input data in the program and provide support to people who are already at this level of leadership in "Gazprom" and properly prepare those who will likely be nominated on the board in the coming years. This system was also used in a course of management of Kazakhstan, Czech Republic, Australia, South Africa, India, Indonesia, Sweden and Germany. (Mylner, 2006)

As the complexity and variability in the environment continue to grow, external (need for information about what is going on around) and internal focus (ability to generate public education knowledge based on this information) will be even more powerful engines of management and organization design. Command and supervisory structure will continue to change in the direction of distributed control and decision-making directly immediately in response to the environment. Combating major shareholder Anglo-Saxon countries the economy is likely to remain strong, but because other systems consolidation of capital (e.g. buyout by a loan) have become commonplace, changes in relationships with suppliers of capital are likely to be done in the direction of support for distributed control and immediate response from the larger number of stakeholders.

The most powerful engine of global management are will and personal information technology. Internet has connected organizations around the world to obtain information that can be used to ensure competitiveness. Dissemination of information also has a strong influence on individual development, as it can provide tailored to the needs of the individual study at any time, in any place and at any pace. This training is also beyond the control of the rulers of the manager: "There is no central repository of knowledge on the net, but the curators of certain ideas" (Davenport, 1993).

\section{CONCLUSION}

Focusing on the environment and the need to make the most of the information gathered is likely to reinforce the need for people, who will use their individual assessment in order to understand what information may be relevant to them, and then give the value of the information and manipulate it to achieve maximum benefits. It will also strengthen the need for people who will share information and thus produce added value. However, people will realize their decision to cooperate and only if between the organization and there is mutual trust 
that will not develop because it is "good to have ", or because people like to be "patronized", but the specific reasons for the viability. This need is likely to allow some of the dilemmas in current practice, but not by the transition from command and control to supervisory concern and cooperation, and by the renewal of contracts of employment so that they take into account the need for a "deliberate confidence". This is not a global feeling of warmth or affection, but rather a conscious adjustment depending on one person or another.
It is not something to take for granted, but it must be implemented and supported by reliable commitments made between people who work together, regardless of whether they are in the same unit, the same organization and the same culture, or they are independent contractors who work on a long term or short term basis. Reliable management contracts with reciprocal obligations are likely to be matched to the primary managers of any organization.

\section{WORKS CITED}

Anon. (1988). GablerWirtschafts-Lexikon. Taschenbuch-Kassettemit 6Bd. Wiesbaden: Gabler.

Burng, T., \& Stalker, D. (1961). The Management of innovation. London.

Congress, US. (1995). Innovation and Commercialization of Emerging Technologies. Washington DC: Congress of the U.S. Office of Technology Assessment.

Davenport, T. (1993). Business Innovation, Reengineering Work through Information Technology. Boston, MA: Harvard Business School Press.

Granstrand, J. (2000). The Economics and Management of Intellectual Property. Towards Intellectual Capitalism.Aldershot: Edward Elgar Pub (February 2000).

Hinterhuber, H. (1991). StrategischeUnternehmungsfuhrung: StrategischesDenken: Vision, Unternehmungspolitik, Strategie. New York: De GruyterLehrbuch.

Keynes, J. M. (2002). General Theory of employment, interest and of money / John Maynard Keynes. Moscow: Helios ART.

Koch, R. (1998). The 80/20 Principle: The Secret of Achieving More With Less. New York: Nicholas BrealeyPublising.

Koch, R. (1999). 80-20 Principle. Doubleday.

Martin, L., \&Midgley, C. (1996). Transforming school Cultures. West viev press. A.Dision of Harper Collins Publisners,.

Meskon, M. H. (1992). Fundamentals of management. Moscow: Delo.

Morhunov, E. (2001). Models and methods of personnel management: the Russian-British training manual. Moscow: ZAO "Business School" "Intel-Synthesis".

Mylner, B. (2006). Koncepcyyaorhanyzacyonnigyzmenenyj v sovremennojkompanyy. Problems of the theory and practice of management(2), 8-16.

Pareto, V. (1906). Manuale di economiapolnica. Milan: Societàeditricelibraria.

Poole, M., \&Uornera, M. (2002). Resource Management chelovecheskymy. St. Petersburg: Piter.

Shein, E. (1985). Organizational Culture and Leadership. San Francisko: Jossey - Bass.

Skone, T. (1995). Management accounts: How to use them to control your business. Gower.

Vyssema, H. (2000). Strategicheskijmenedzhmentipredprinimatel'stvo: vozmozhnostidljaprocvetanijabudushhego.Moskow: Izdatel'skijdom «Finansy».

Weissman, A. (1992). Management-Strategien: funfFaktoren fur den Erfolg.Landsberg/Lech: Verl. Modernelndustrie. 
Received for publication: $\quad 25.03 .2014$

Revision received: $\quad 29.05 .2014$

Accepted for publication: $\quad 23.06 .2014$

How to cite this article?

Style - APA Sixth Edition

Shterma, T. (2014, 07 15). Socioeconomic and organizational context of management. (Z. Čekerevac, Ed.) MEST Journal, 2(2), 214-223. doi:10.12709/mest.02.02.02.22

Style - Chicago Fifteenth Edition:

Shterma, Tatiana. 2014. "Socioeconomic and organizational context of management." Edited by Zoran Čekerevac. MEST Journal (MESTE) 2 (2): 214-223. doi:10.12709/mest.02.02.02.22.

Style - GOST Name Sort:

Shterma Tatiana Socioeconomic and organizational context of management [Journal] // MEST Journal / ed. Čekerevac Zoran. - Belgrade : MESTE, 07 15, 2014. - 2 : Vol. 2. - pp. 214-223.

Style - Harvard Anglia:

Shterma, T., 2014. Socioeconomic and organizational context of management. MEST Journal, 1507 , 2(2), pp. 214-223.

Style - ISO 690 Numerical Reference:

Socioeconomic and organizational context of management. Shterma, Tatiana. [ed.] Zoran Čekerevac. 2, Belgrade : MESTE, 07 15, 2014, MEST Journal, Vol. 2, pp. 214-223. 